\title{
c-Myc induces cytochrome $c$ release in Rat1 fibroblasts by increasing outer mitochondrial membrane permeability in a Bid-dependent manner
}

\author{
I laccarino ${ }^{1,2}$, D Hancock ${ }^{1}$, G Evan $^{3}$ and J Downward*,1 \\ ${ }^{1}$ Cancer Research UK, London Research Institute, 44, Lincoln's Inn Fields, \\ London WC 2A 3PX, UK \\ 2 Istituto di Genetica e Biofisica 'Adriano Buzzati Traverso', CNR, Via Marconi \\ 10, 80125 Napoli, Italy \\ ${ }^{3}$ UCSF Cancer Centre, 2340 Sutter Street, San Francisco, CA 94143-0875, \\ USA \\ * Corresponding author: J Downward, Cancer Research UK, London Research \\ Institute, 44, Lincoln's Inn fields, London WC 2A 3PX, UK. \\ E-mail: julian.downward@cancer.org.uk
}

Revised 4.12.02; accepted 6.12.02

Edited by G Melino

\begin{abstract}
Ectopic expression of c-myc sensitises cells to a wide range of apoptotic stimuli by inducing the release of cytochrome $c$ from the mitochondrial intermembrane space into the cytosol. To elucidate the molecular mechanisms of mitochondrial permeabilisation in response to c-Myc activation, we carried out a biochemical fractionation analysis of Rat1 fibroblasts expressing an inducible c-Myc protein. We find that cytoplasmic extracts from cells in which c-Myc has been activated contain a soluble factor capable of inducing cytochrome $c$ release from isolated mouse liver mitochondria. This factor is present only under growth factor deprivation conditions and its activity is inhibited by addition of $\mathrm{BCl}-\mathrm{X}_{\mathrm{L}}$. The c-Myc-induced factor copurifies with full-length Bid, a "BH3-only" proapoptotic member of the Bcl-2 family, and antibodies raised against the $\mathrm{BH} 3$ domain of Bid inhibit CMyc-induced cytochrome $c$ releasing activity. These results are consistent with a model in which the activation of c-Myc regulates factors capable of enhancing the mitochondrial membrane destabilisation function of "BH3-only" proteins.

Cell Death and Differentiation (2003) 10, 599-608. doi:10.1038/ sj.cdd. 4401211
\end{abstract}

Keywords: c-Myc; apoptosis; mitochondria; cytochrome c; Bid; Bax; $\mathrm{BH} 3$

Abbreviations: 4-OHT, 4-hydroxytamoxifen; OMM, outer mitochondrial membrane; FCS, foetal calf serum; DMEM, Dulbecco's modified Eagle medium; PMSF, phenylmethylsulphonyl fluoride; IGF-1, insulin-like growth factor 1.
Introduction

The proto-oncogene $c$-myc is involved in a wide range of cellular processes, including proliferation, differentiation and apoptosis. c-Myc is a transcription factor belonging to the basic helix-loop-helix zipper (bHLHZ) family. All the activities so far attributed to c-Myc require its ability to modulate transcription. In most cases, however, the target genes and the pathways regulated by c-Myc remain elusive (see Grandori et al. ${ }^{1}$ for a review). Among the different c-Myc activities, the ability to promote apoptosis is one of the most intriguing. It has been established that rather than inducing apoptosis per se, c-Myc sensitises many cell types to different apoptotic stimuli. ${ }^{2}$ The ability to promote both proliferation and apoptosis has been proposed as a way to restrain the emergence of neoplastic clones within the soma and seems to be shared by a number of other oncogenes. $^{2-4}$

The overexpression of the proto-oncogene $\mathrm{Bcl}-2$ strongly cooperates with c-Myc both in cell transformation in vitro and in oncogenesis in vivo. ${ }^{5,6}$ This cooperativity is likely to act by the ability of Bcl-2 to abrogate the apoptotic function of c-Myc. $\mathrm{Bcl}-2$ is the founder of a family of proteins with both antiapoptotic (Bcl-2, Bcl- $\left.\mathrm{X}_{\mathrm{L}}, \mathrm{A} 1, \mathrm{Mcl} 1, \mathrm{Bcl}-\mathrm{W}\right)$ and proapoptotic (Bax, Bak, Bid, Bad, Bik, Hrk, Bim, Noxa, Puma) functions. ${ }^{7}$ The antiapoptotic proteins $\mathrm{Bcl}-2$ and $\mathrm{Bcl}-\mathrm{X}_{\mathrm{L}}$ are integral membrane proteins localised in the mitochondria and the endoplasmic reticulum. ${ }^{8,9} \mathrm{Bcl}-2, \mathrm{Bcl}-\mathrm{X}_{\mathrm{L}}$ and possibly the other antiapoptotic members of the family protect mitochondrial integrity by regulating the outer mitochondrial membrane (OMM) permeability and the activity of metabolite exchange channels. $^{10,11}$ The mechanism by which $\mathrm{Bcl}-2$ and $\mathrm{Bcl}-\mathrm{X}_{\mathrm{L}}$ exert their protective role is currently unknown, but it seems to require domains affecting the heterodimerisation with proapoptotic members of the same family (Bax, Bak, Bid, etc.) as well as domains affecting a putative channel-forming activity. $^{12}$

The proapoptotic members of the Bcl-2 family fall into two subsets. The so-called multidomain factors are proteins sharing more than one homology domain, like Bax and Bak. The other subfamily comprises proteins sharing only the $\mathrm{BH} 3$ domain. These 'BH3-only' proteins are often downstream effectors of signalling pathways. They are usually constitutive active peptides inactivated by survival signals or freed from inactivators following diverse cellular stresses. For example, Bad is sequestered in an inactive cytoplasmic complex by 143-3 after being phosphorylated by survival kinases. ${ }^{13}$ Bim is kept separate from mitochondria by binding to dynein light chain in healthy cells and is released after cellular stress, migrating to mitochondrial membranes. ${ }^{14}$ In the multidomain subfamily Bak is an integral OMM protein both under normal and apoptotic conditions. Bax, early after the apoptotic 
stimulus, migrates to the OMM following a conformational change. The 'BH3-only' protein Bid may be involved in mediating the conformational change of Bax. ${ }^{15}$ Destabilisation of the OMM following Bax conformational change results in the release of cytochrome $c$ and other apoptotic proteins from the intermembrane space, as well as activation of the caspase-9-dependent apoptotic pathway.

Cytochrome $c$ release from the mitochondria is a key step in c-Myc-induced sensitisation to apoptosis. ${ }^{16}$ Presumably, cMyc activation has a direct effect on the OMM permeability, reducing the threshold for a complete membrane destabilisation and therefore cooperates with other stimuli that trigger the mitochondrial apoptotic pathway.

The mechanism by which c-Myc destabilises the OMM is not known. It might involve the upregulation of cytosolic factors causing membrane destabilisation or the downregulation of protective factors located in the mitochondria. In the present study, we approach the problem by using an in vitro fractionation analysis to discern between these two possibilities. We show that cytosolic extracts from Rat1 fibroblasts expressing the conditional c-Myc fusion protein (MycER ${ }^{\mathrm{TM}}$ ) contain a soluble factor capable of releasing cytochrome $c$ from isolated mouse liver mitochondria. This is present only under conditions where c-Myc has been activated. Fractionation studies show that this factor copurifies with full-length Bid, a proapoptotic member of the $\mathrm{Bcl}-2$ family. We propose that cMyc regulates factors capable of enhancing the membrane destabilisation function of 'BH3-only' proteins.

\section{Results}

Using a chimeric protein obtained by fusing c-Myc with a modified version of the oestrogen receptor $\left(\mathrm{MycER}^{\mathrm{TM}}\right),{ }^{17}$ it has been shown that activation of c-Myc is followed by an early redistribution of cytochrome $c$ from the mitochondria to the cytoplasm. ${ }^{16}$ The mechanisms by which c-Myc increases mitochondrial membrane permeability could involve regulation of cytosolic factors or a direct action on a component of the mitochondrial membrane. To discriminate between these two possibilities, we made use of mitochondria purified from a source external to the system. We set up an in vitro assay in which mitochondria purified from mouse liver are incubated with the soluble cytoplasmic fraction of cell extracts from Rat1 fibroblasts expressing $M_{y c E R}{ }^{\mathrm{TM}}$. We reasoned that if a cytosolic factor responsible for cytochrome $c$ relocalisation is a c-Myc-regulated target, this should induce a similar relocalisation in mitochondria purified from mouse liver. cMyc-induced apoptosis in Rat1/MycER ${ }^{\mathrm{TM}}$ cells starts to be evident after $8 \mathrm{~h}$ of 4-hydroxytamoxifen (4-OHT) addition (Figure 1), and at this time, cells with relocalised cytochrome $c$ start to appear in the cell population. ${ }^{16}$ We therefore decided to analyse extracts from cells incubated for $8 \mathrm{~h}$ with $4-\mathrm{OHT}$. As shown in Figure $2 \mathrm{a}$, after $1-\mathrm{h}$ incubation almost $90 \%$ of the cytochrome $c$ was released from the mitochondria incubated with these extracts (+4-OHT lanes). Interestingly, the cytochrome $c$ releasing activity could be almost totally inhibited by the addition of recombinant $\mathrm{Bcl}-\mathrm{X}_{\mathrm{L}}$ protein. Rat1/MycER ${ }^{\mathrm{TM}}$ cells grown in the presence of $10 \%$ serum do not show any apoptotic features, even in presence of $4-\mathrm{OHT}$ (data not

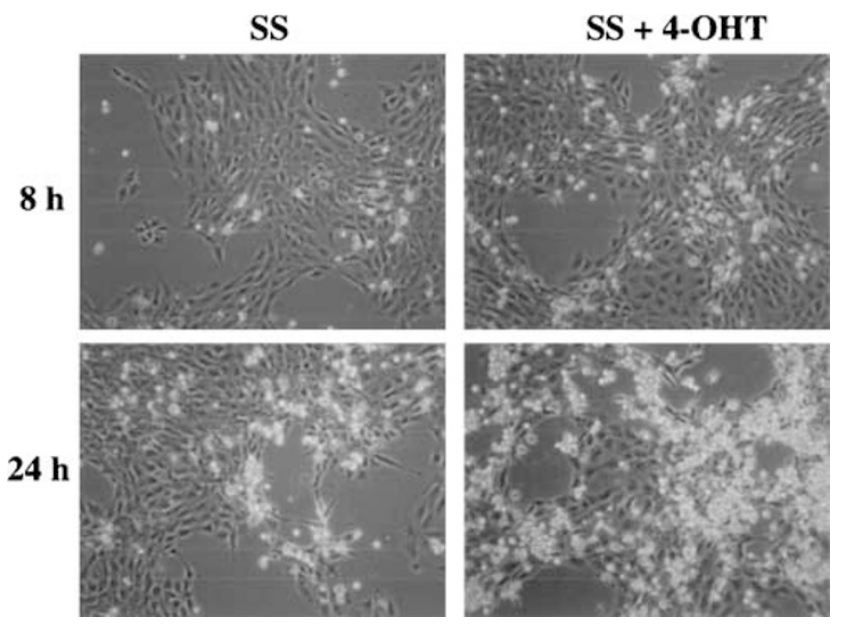

Figure 1 Apoptosis induced by activation of c-Myc in serum-starved Rat1 fibroblasts. The Rat1/MycER ${ }^{\mathrm{TM}}$ clone G2 ${ }^{17}$ was serum starved for $24 \mathrm{~h}$. In the right panels, $100 \mathrm{nM} 4-\mathrm{OHT}$ was added to the samples in serum-free medium, respectively, for 8 and $24 \mathrm{~h}(\mathrm{SS}+4-\mathrm{OHT})$. Pictures of serum starved-only cells (SS) are shown in the left panels

shown). Protein extracts from cells grown in $10 \%$ foetal calf serum (FCS) (Figure 2, lane 10\% FBS + 4-OHT) are essentially devoid of cytochrome $c$ releasing activity.

Serum-starved Rat1/MycER ${ }^{\mathrm{TM}}$ cells grown in the absence of 4-OHT showed some degree of cytochrome $c$ releasing activity (data not shown). This could be because of either lack of specificity of the activity found or leaky regulation of the inducible system used (ER fusion). To discriminate between these two possibilities, we measured the cytochrome $c$ releasing activity of extracts obtained from cells serum starved for $24 \mathrm{~h}$ and then treated or untreated for $8 \mathrm{~h}$ with 4$\mathrm{OHT}$. The results shown in Figure $2 \mathrm{~b}$ demonstrate that addition of 4-OHT to the cells is responsible for a three-fold increase in activity, suggesting a direct connection between cMyc activation and cytochrome $c$ releasing activity. Furthermore, extracts from Rat 1 fibroblasts containing only the vector plasmid (pBABEpuro) do not show any cytochrome $c$ releasing activity, even after $48 \mathrm{~h}$ of serum starvation, suggesting that the observed activity is c-Myc-specific (Figure 2a, Rat1 SS).

Based upon the above experiments, we started a fractionation of cytoplasmic extracts from Rat $1 / \mathrm{MycER}^{\mathrm{TM}}$ cells that had been serum starved $24 \mathrm{~h}$ and treated with $4-\mathrm{OHT}$ for $8 \mathrm{~h}$. When the cell extract was loaded onto a $Q$ Sepharose column, a cytochrome $c$ releasing activity eluted as a single peak at around $300 \mathrm{mM} \mathrm{NaCl}$ (Figure 3, panel A). The pooled active fractions were further fractionated using a Superdex 200 gel filtration chromatography column. The activity eluted as a single peak with an elution volume corresponding to an apparent molecular weight (MW) of $25 \mathrm{kDa}$ (Figure 3, panel B).

Several proapoptotic members of the $\mathrm{Bcl}-2$ protein family have been shown to induce the release of cytochrome $c$ from purified mitochondria in vitro. ${ }^{19-21}$. In order to determine if one of these proteins is responsible for the c-Myc-dependent cytochrome $c$ releasing activity in Rat1 fibroblasts, we probed active fractions from both columns for the presence of the 
a

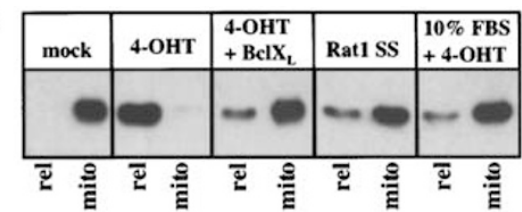

b

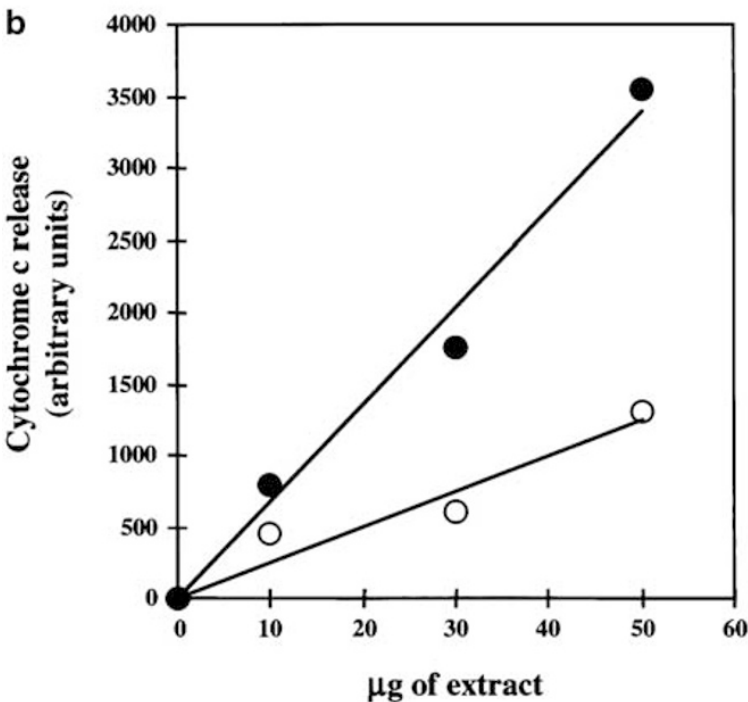

Figure 2 Extracts of cells expressing c-Myc induce cytochrome $c$ release from purified mouse liver mitochondria. (a) Analysis by immunoblot for cytochrome $c$. Purified mitochondria were incubated with cytosolic cell extracts as described in Materials and Methods. After centrifugation, both the supernatant (rel) and the pellet (mito) were analysed. The 'mock' sample was incubated with reaction buffer only. The following extracts were used: Rat $1 / \mathrm{MycER}^{\mathrm{TM}}$ cells serum starved for $24 \mathrm{~h}$ and incubated with $4-\mathrm{OHT}$ for $8 \mathrm{~h}(4-\mathrm{OHT})$; the same extract in the presence of $4 \mathrm{ng}$ of recombinant $\mathrm{Bcl}-\mathrm{X}_{\mathrm{L}}\left(4-\mathrm{OHT}+\mathrm{Bcl}-\mathrm{X}_{\mathrm{L}}\right)$; Rat $1 / \mathrm{pBABE}$ serum starved for $24+8 \mathrm{~h}$ (Rat1 SS); Rat $1 / \mathrm{MycER}^{\mathrm{TM}}$ cells grown in $10 \% \mathrm{FBS}$ and treated with $4-\mathrm{OHT}$ for $8 \mathrm{~h}(10 \% \mathrm{FBS}+4-\mathrm{OHT})$. (b) Increasing amounts of protein extracts were tested for their ability to induce the release of cytochrome $c$ from purified mitochondria at $0,1,2$ and $3 \mathrm{~h}$ of incubation. The rate of the release (amount of cytochrome $c$ released per hour) was plotted against the amount of extract used. Extracts from Rat $1 \mathrm{MycER}^{\mathrm{TM}}$ cells treated with 4-OHT are indicated by filled circles. Extracts from the same cells, serum starved only, are indicated by open circles

soluble members of the Bcl-2 protein family, Bax and Bid. As shown in Figure 4 , the cytochrome $c$ releasing activity coeluted with Bid, both from the Q Sepharose column and from the S200 column.

Bid is a 23-kDa protein that has been shown to be cleaved following caspase-8 activation. Bid cleavage induces a more than 10 -fold increase in cytochrome $c$ releasing activity with respect to full-length Bid, both in vitro and in vivo. ${ }^{19,22}$ It is therefore possible that c-Myc regulates cytochrome $c$ release in the cells by modulation of the cleavage status of Bid. Alternatively, c-Myc may, directly or indirectly, induce an increase in Bid expression level. As shown in Figure 5 (panel a), no trace of the $15 \mathrm{kDa}$ Bid cleavage product is present in Rat1/MycER ${ }^{\mathrm{TM}}$ extracts after addition of $4-\mathrm{OHT}$. The only immunoreactive material detected runs with an apparent MW of $23 \mathrm{kDa}$, corresponding to the full-length Bid. The same apparent MW is associated with the Bid immunoreactive band present in the partial purified activity (Figure 5, panel a, lane pool QFF). To show that, despite the absence of Bid cleavage product after 4-OHT addition, rat Bid could be cleaved by
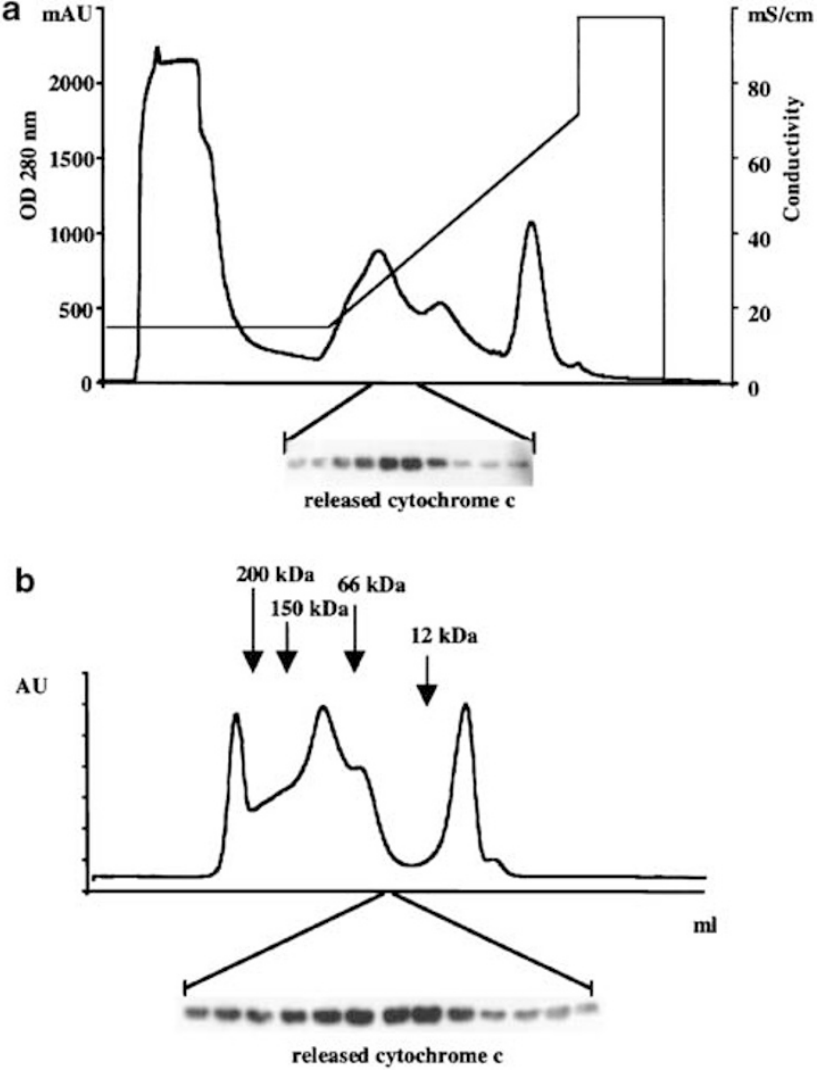

Figure 3 Chromatographic analysis of the c-Myc-induced cytochrome $c$ releasing activity. In panel a, $200 \mathrm{mg}$ of protein extract from 4-OHT-treated Rat1MycER ${ }^{\mathrm{TM}}$ cells were loaded onto a $20 \mathrm{ml}$ QFF anion exchange column. After washing, the column was eluted with a linear salt gradient. An aliquot of the fractions was tested for cytochrome $c$ releasing activity on purified mitochondria. The fractions active for cytochrome $c$ release eluted around $300 \mathrm{mM} \mathrm{NaCl}$. Panel $b$, active fractions from the QFF column were pooled, concentrated and loaded on a 26/30 S200 Gel filtration column. The cytochrome $c$ releasing activity eluted with an apparent native MW of $25 \mathrm{kDa}$. The column had been previously calibrated using the following proteins as MW standards: $\beta$-amylase, alcohol dehydrogenase, bovine serum albumin, carbonic anhydrase and cytochrome $c$

caspase-8, we incubated the same extract with recombinant active caspase-8. As shown in Figure 5 (panel b), after addition of recombinant caspase-8, the 23-kDa Bid immunoreactive band is completely converted to a faster migrating band with an apparent MW of $15 \mathrm{kDa}$. Figure 5 also shows that the induction of C-Myc does not produce any increase of Bid protein level, excluding the possibility that Bid is transcriptionally regulated by c-Myc.

Proapoptotic members of the $\mathrm{Bcl}-2$ protein family have been shown to be regulated at the post-translational level. Bad, for example, is inactivated by phosphorylation through the action of Akt and several other kinases. ${ }^{13,23}$ Bid itself has been shown to be myristoylated after cleavage, ${ }^{24}$ and recent evidence for phosphorylation has also been reported for Bid. ${ }^{25}$ c-Myc activation might therefore regulate Bid activity by changing its post-translation modification status. To answer this question, we performed a two-dimensional electrophoresis analysis on cytoplasmic extracts from Rat $1 / \mathrm{MycER}^{\mathrm{TM}}$ cells treated with or without 4-OHT for $8 \mathrm{~h}$ in the absence of serum. On a 3-10 $\mathrm{pH}$ range the only Bid immunoreactive 
a Anion exchange chromatography

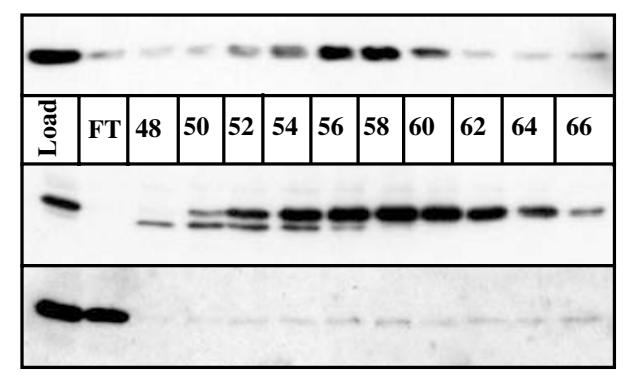

CytoC

Bid

Bax

\section{b Size exclusion chromatography}

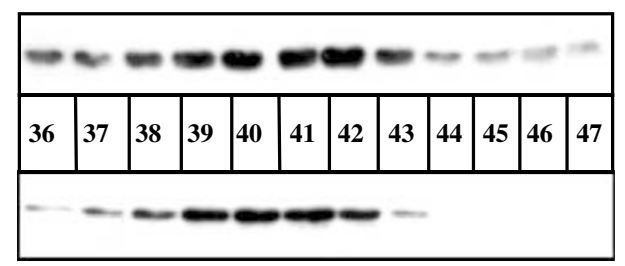

CytoC

Bid

Figure 4 The proapoptotic member of the Bcl-2 protein family, Bid, copurifies with the cytochrome $c$ releasing activity. Fractions from the QFF column (panel a) and from the S200 column (panel b) are tested for the presence of the proapoptotic proteins Bid and Bax. In the upper part of each panel is shown the amount of cytochrome $c$ released from purified mouse mitochondria after incubation with the indicated samples
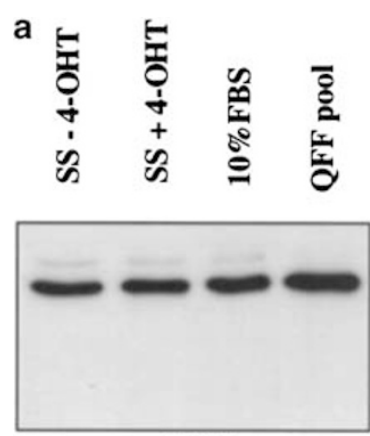

anti-Bid b

Casp.8

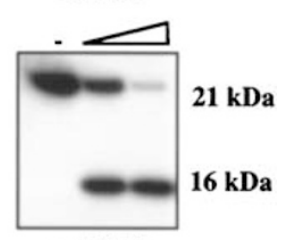

anti-Bid
Figure 5 Induction of c-Myc does not increase Bid level or induce its cleavage. Immunoblot analysis of endogenous Bid in Rat1 cell extracts. In lanes 1 and 2 (panel a), the cells were serum starved for $24 \mathrm{~h}$ and then incubated for $8 \mathrm{~h}$ in the presence or absence of 4-OHT, in serum-free medium. In lane 3 , the cells were grown in the presence of $10 \%$ FBS. Lane 4 was loaded with an aliquot of the pool from the QFF column used to fractionate the protein extract shown in lane 2, and containing all the cytochrome $c$ releasing activity. In panel b, $30 \mu \mathrm{g}$ of extract were treated with 20 and $100 \mathrm{ng}$ of recombinant active caspase-8 (Pharmingen) for $30 \mathrm{~min}$ at $30^{\circ} \mathrm{C}$

material was a single spot with a pl around 5 . When we narrowed the $\mathrm{pH}$ range to a single unit, Bid was focusing as a doublet, with a pattern typical of a phosphorylation shift (Figure 6). Bid has recently been shown to be phosphorylated by casein kinase I and $11 .{ }^{25}$ The phosphorylation has been shown to be on the Ser61 and Ser64 and to be responsible for an increased resistance of the protein to caspase-8 cleavage. Figure 6 shows that, despite the presence of a phosphorylation pattern associated with rat Bid, no difference was

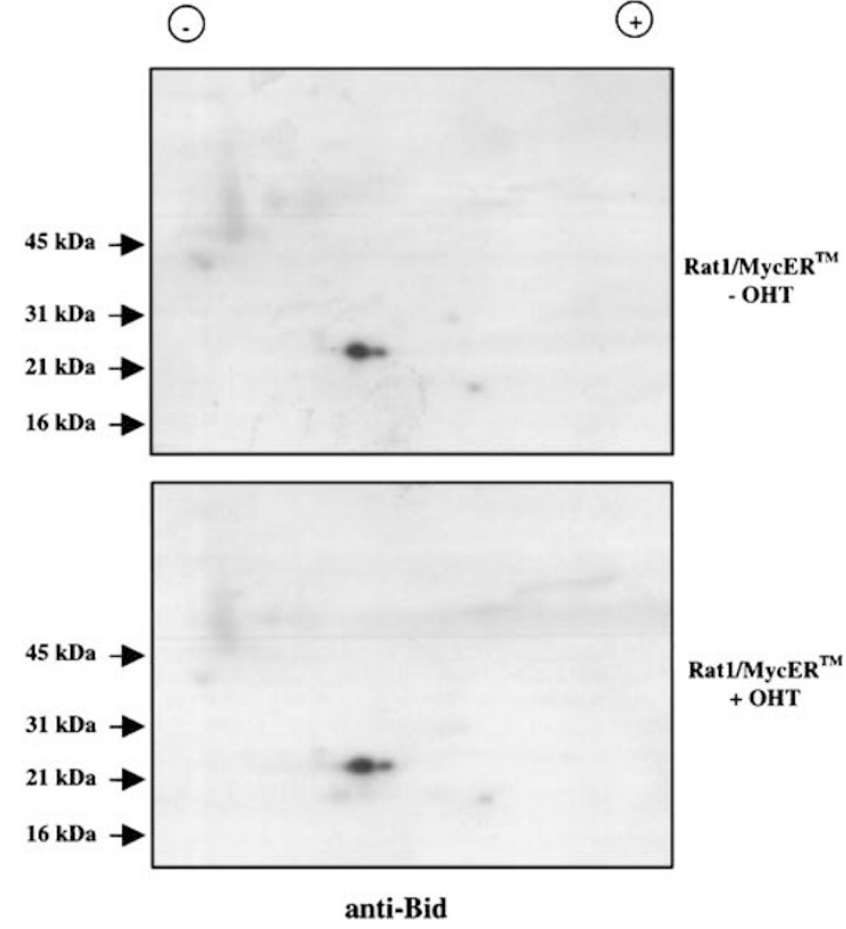

Figure 6 2D-gel analysis of Rat1/MycER ${ }^{\mathrm{TM}}$ cell extracts. Immunoblot analysis of endogenous Bid in Rat 1 cell extracts. Total extracts from $2 \times 10^{6}$ cells were focused on a pH 3-10 $18 \mathrm{~cm}$ IEF strip (Amersham Biosciences). A $7 \mathrm{~cm}$ length of the strip corresponding to the $\mathrm{pH}$ interval 5-6 were cut and loaded on a $15 \%$ SDS-PAGE. Extracts from Rat1/MycER ${ }^{\mathrm{TM}}$ cells serum starved $24 \mathrm{~h}$ and then treated (lower panel) or not (upper panel) with $100 \mathrm{nM} 4-\mathrm{OHT}$ were analysed.

detectable between extracts of Rat $1 / \mathrm{MycER}^{\mathrm{TM}}$ cells treated or not with 4-OHT.

Since c-Myc does not induce changes in the level of expression of Bid or its post-translation modification, we investigated the possibility that Bid could be bound in an inactive complex under conditions in which c-Myc is not active, and released upon induction of c-Myc. We performed a gel filtration analysis on extracts from Rat $1 / \mathrm{MycER}^{\mathrm{TM}}$ treated with or without 4-OHT reasoning that, if Bid is complexed with an 'inactivator', this should result in a shift in apparent MW on the gel filtration analysis. No difference in the elution volumes profiles was detectable using size exclusion chromatography (data not shown), suggesting that if such an inactivator exists it must be relatively small.

To address the possibility that c-Myc could regulate the expression or the activity of a factor essential for Bid functioning, we produced recombinant Bid and used it in complementation studies. As has been shown previously, ${ }^{26}$ purified recombinant Bid is incapable of inducing cytochrome $c$ release from mouse liver mitochondria in the absence of $\mathrm{Mg}$ ions (Figure $7 \mathrm{a}$, lane 1). To investigate if cell extracts could complement Bid for cytochrome $c$ releasing activity, we added to the same amount of purified Bid protein different cytoplasmic extracts. In this experiment, extracts from Rat1 fibroblasts grown in the presence of serum (lane 2) or extracts from Rat $1 / \mathrm{MycER}^{\mathrm{TM}}$ cells grown in the absence of 4-OHT (lane 3) show no cytochrome c releasing activity. To detect a possible increase in cytochrome $c$ releasing activity because 
a
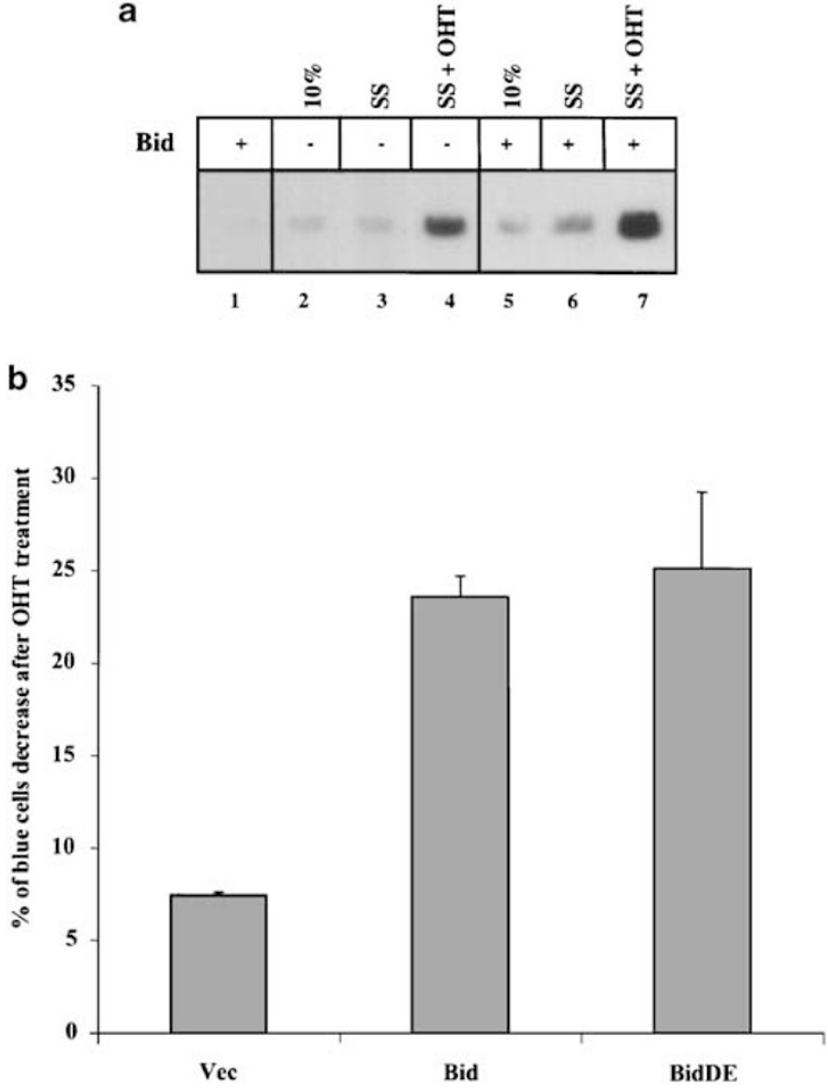

Figure 7 Full-length Bid synergises with c-Myc both in vitro and in vivo. Immunoblot analysis of cytochrome $c$ released from purified mouse liver mitochondria (panel a). Mitochondria were incubated either with 3 pmoles of recombinant Bid alone, or Bid together with $30 \mu \mathrm{g}$ of the indicated cell extracts. Lanes 2 and 5: extract from Rat1/MycER ${ }^{\mathrm{TM}}$ cells grown in $10 \%$ serum; lanes 3 and 6: extract from Rat1/MycER ${ }^{\mathrm{TM}}$ cells serum starved for $24 \mathrm{~h}$; lanes 4 and 7 : extract from Rat $1 / \mathrm{MycER}^{\mathrm{TM}}$ cells serum starved for $24 \mathrm{~h}$ and treated with $4-\mathrm{OHT}$ for $8 \mathrm{~h}$. In panel $\mathrm{b}$, Rat1/MycER ${ }^{\mathrm{TM}}$ cells were cotransfected with the LacZ reporter gene and either the empty vector ( $\mathrm{Vec}$ ), or the vector expressing wt Bid (Bid) or a noncleavable mutant of Bid (BidDE). Cells were starved in $1 \%$ FCS for $24 \mathrm{~h}$ and then treated with or without $4-\mathrm{OHT}$ for $16 \mathrm{~h}$ in $1 \% \mathrm{FCS}$. The percentage of blue cells was counted in each sample. The graph, result of the experiment carried in duplicate, shows the percentage decrease in blue cells over the total in samples treated with 4-OHT with respect to the untreated controls. A 4-OHT-specific reduction in the number of blue cells over the total is a measure of synergism between c-Myc and the tested proteins

of the presence of recombinant Bid in the reaction, conditions were chosen to give nonsaturated cytochrome $c$ release. Using this approach, extracts from Rat $1 / \mathrm{MycER}^{\mathrm{TM}}$ cells grown in the presence of $4-\mathrm{OHT}$ induce the release of only $30-40 \%$ of the total cytochrome $c$ from mitochondria (lane 4 and data not shown). As shown in Figure 7a (lane 7), only extracts in which c-Myc has been activated produced a significant increase in Bid activity. The very small activation given by the extract from Rat1/MycER ${ }^{\mathrm{TM}}$ cells grown in the absence of OHT (compare lane 3 and 6 ) could be explained by the slight leakiness of the system (compare with Figure $2 b$ ).

The synergy of extracts containing activated c-Myc with pure recombinant Bid in eliciting cytochrome $c$ releasing activity and the absence of any Bid cleavage product in this system (see Figure 5) led us to test if Bid and a noncleavable Bid mutant (Bid D60E) was able to exacerbate c-Myc-induced apoptosis. In order to do this, pcDNA3.1, pcDNA3.1/BIDhis or pcDNA3.1/BID-D60Ehis were cotransfected together with pcDNA3.1/LacZ, as a gene reporter, into Rat1/MycER ${ }^{\mathrm{TM}}$ cells. After serum starvation and 4-OHT treatment, cells were fixed and stained for $\beta$-galactosidase activity. As shown in Figure $7 \mathrm{~b}$, the percentage of blue-stained cells, upon Bid cotransfection (Bid), showed a significant and reproducible decrease after 4-OHT treatment, compared with the sample cotransfected with vector alone, indicating that c-Myc-induced sensitisation to apoptosis was further increased by the expression of Bid. The same decrease was observed in cells cotransfected with a plasmid carrying Bid mutated in the caspase-8 cleavage site (Bid D60E), indicating that the synergistic effect observed in this experiment is independent of caspase-8-mediated Bid cleavage.

The data presented in Figure 7 suggest that activation of cMyc does not influence Bid directly, but that it regulates a second soluble factor that, in turn, regulates Bid activity. In this scenario, Bid could be dispensable for c-Myc-induced cytochrome $c$ activity, if another proapoptotic member of the Bcl-2 protein family could substitute for it. To address this question, we used antibodies directed against the $\mathrm{BH} 3$ domain of Bid to inhibit c-Myc-induced cytochrome $c$ activity. As shown in Figure 8, an antibody recognising the $\mathrm{Bid} \mathrm{BH}$ domain inhibits the $\mathrm{c}-\mathrm{Myc}$-induced cytochrome $c$ releasing activity in a dose-dependent manner. The same result was obtained using a commercial antibody raised against fulllength Bid peptide (data not shown). In contrast, no inhibitory effect was seen using the same amount of an antibody directed against the $\mathrm{BH} 3$ domain of the proapoptotic $\mathrm{Bcl}-2$ family protein Mtd/Bok, suggesting that Bid is necessary for cytochrome $c$ release in this system.

We have shown that Bid plays an important role in the cytochrome $c$ relocalisation induced by c-Myc. It was recently shown that in HeLa cells, Bid induces the oligomerisation and insertion of Bax in the OMM by changing its conformational status. ${ }^{15}$ It is possible to detect conformational changes of Bax in vivo using a monoclonal antibody raised against its $\mathrm{N}$ terminus (Mab 6A7). ${ }^{15,27,28}$ The epitope recognised by Mab 6 A7 becomes exposed only after an apoptotic stimulus. We therefore investigated whether activation of c-Myc could influence the conformational status of Bax in vivo, by measuring the immunoreactivity of Bax to the Mab 6A7 in Rat1/MycER ${ }^{\mathrm{TM}}$ cells treated with or without 4-OHT. As shown in Figure 9, activation of c-Myc markedly increases the number of cells positive for Mab 6A7 staining, suggesting that c-Myc promotes conformational activation of Bax.

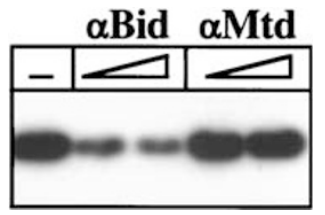

Figure 8 Antibodies raised against Bid BH3 domain inhibit c-Myc-induced cytochrome $c$ releasing activity. Immunoblot analysis of cytochrome $c$ released from purified mouse liver mitochondria. Mitochondria were incubated with extract from Rat $1 / M_{y c E R}{ }^{\text {TM }}$ cells serum starved for $24 \mathrm{~h}$ and treated with $4-\mathrm{OHT}$ for $8 \mathrm{~h}$, in the presence of increasing amounts $(2$ and $5 \mu \mathrm{g})$ of purified polyclonal antibodies raised against the $\mathrm{BH} 3$ peptides of Bid (aa 82-106 of the mouse sequence) or MTD/Bok (aa 63-87 of the mouse sequence) 

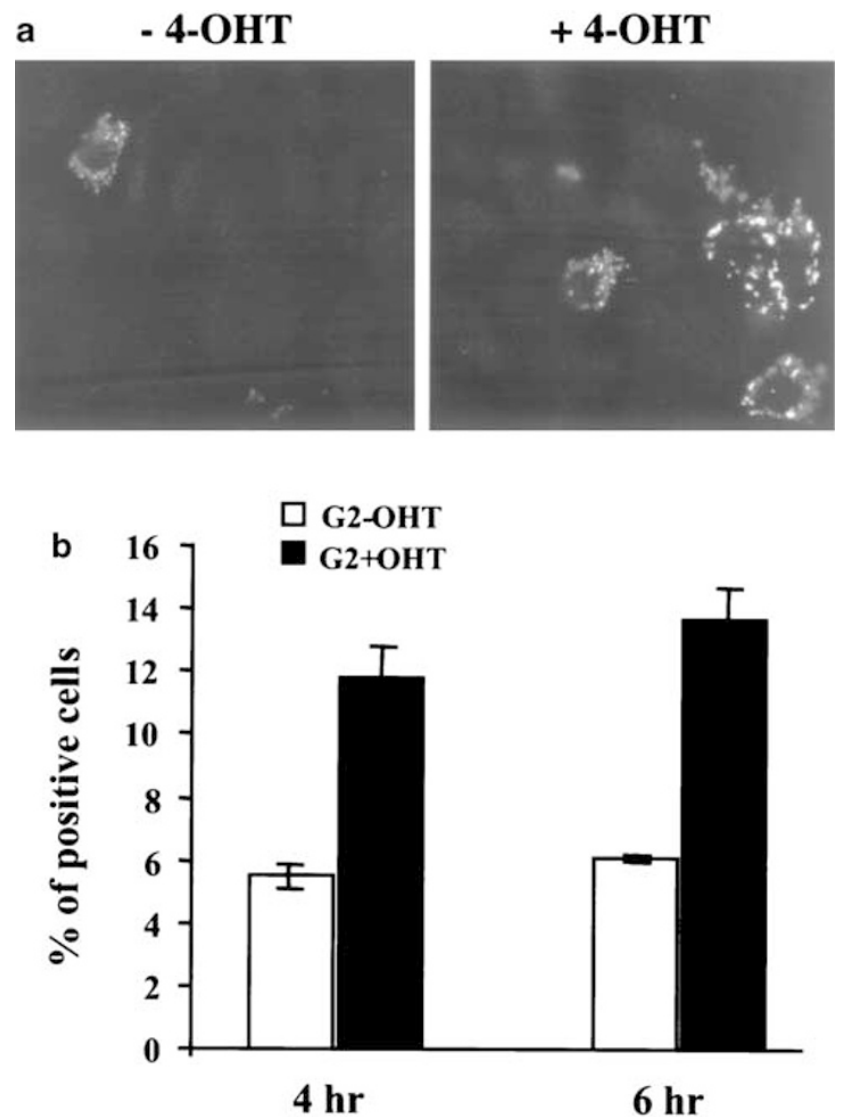

Figure 9 Treatment of Rat1/MycER ${ }^{\mathrm{TM}}$ with 4-OHT induces a Bax conformational change. Immunofluorescence analysis of endogenous rat Bax in Rat1/ $\mathrm{MycER}^{\mathrm{TM}}$ cells treated or untreated with $4-\mathrm{OHT}$ for 4 and $6 \mathrm{~h}$. Cell monolayers were fixed by addition of $1 \%$ paraformaldehyde in PBS. Coverslips were washed in PBS and incubated with 6A7 anti-Bax monoclonal antibody (Trevigen). Panel a: representative pictures of cells treated $(+4-\mathrm{OHT})$ or untreated $(-4-\mathrm{OHT})$ with $4-\mathrm{OHT}$ for $6 \mathrm{~h}$. The appearance of a strong perinuclear punctate staining is a measure of a conformational change of Bax. Panel $b$ : percentage of Bax-positive cells quantified by counting a minimum of 500 cells in five randomly chosen fields. Data from untreated cells (G2-OHT) and $4 \mathrm{~h}$ - or $6 \mathrm{~h}-4-\mathrm{OHT}$ treated cells (G2-OHT) is displayed. Positive cells are expressed as a percentage of the total number of cells analysed. Values represent the mean and variation of a typical experiment performed in duplicate.

\section{Discussion}

In order for a cell to become transformed, it must acquire new proliferative capabilities and concomitantly be able to escape apoptotic cell death. Genetic lesions that increase the proliferative capability of cells often affect also their sensitivity to apoptotic stimuli. ${ }^{29}$ This is particularly well described for the oncogene c-myc. Ectopic expression of $c$-myc seems to have a dual effect: on the one hand, it is sufficient to drive cells into mitosis, while on the other hand, it sensitises cells to many apoptotic stimuli, such as growth factor deprivation, Fas ligation, UV damage, TNF $\alpha$ and hypoxia. A better understanding of the molecular pathways downstream of c-Myc could, therefore, give an invaluable insight into the comprehension of the process of neoplastic transformation.

A step towards understanding the way c-Myc sensitises cells to apoptosis came from previous studies. ${ }^{16}$ Using an inducible MycER fusion protein, it was shown that c-Myc

triggers the release of cytochrome $c$ from the intermembrane mitochondrial space into the cytosol. This process is caspase independent and blocked by the survival factor (IGF-1) insulin-like growth factor 1 . Interestingly, c-Myc-induced apoptosis could be blocked by microinjection of anticytochrome $c$ antibodies, and microinjection of holocytochrome $c$ in the cytoplasm of the cells mimicked the effect of c-Myc activation, thus sensitising cells to other apoptotic stimuli. ${ }^{16}$

The mechanism of c-Myc-induced release of cytochrome $c$ from mitochondria may involve either the positive regulation of factors with membrane destabilising action or downregulation of proteins that protect mitochondrial homeostasis, or both. The sensitisation effect shown by c-Myc expression under conditions of growth factors deprivation could be the result of a complex signalling network that affects both mitochondrial and cytosolic factors. We analyse in this paper the effect of cytosolic extracts, obtained from cells in which c-Myc is ectopically expressed, on mitochondria purified from a source external to the system. We observe that cytoplasmic extracts are capable of inducing the release of cytochrome $c$ from the mitochondrial intermembrane space only when they are derived from cells in which c-Myc has been previously activated by the drug 4-OHT. These findings demonstrate that $\mathrm{c}-\mathrm{Myc}$ modulates soluble cytosolic factors with cytochrome $c$ releasing activity. The possibility that $c-M y c$ acts also on mitochondrial components has not been addressed directly.

IGF-1 is a potent inhibitor of c-Myc sensitisation to growth factors deprivation-induced apoptosis. ${ }^{3}$ It has been observed that IGF-1 inhibits the release of cytochrome $c$ from mitochondria induced by c-Myc activation. IGF-1 is a survival factor that activates both the MAPK pathway and the PI3K/Akt pathway through the binding to its receptor tyrosine kinase. Both pathways have been proposed to protect cells from several apoptotic stimuli. ${ }^{30}$ Suppression of c-Myc-induced apoptosis in Rat1 fibroblasts seems to depend exclusively on the PI3K/Akt pathway. ${ }^{31}$ Activation of Akt leads to the engagement of multiple antiapoptotic pathways, either transcription dependent or transcription independent. ${ }^{32}$ Akt has been shown recently to play a pivotal role in the control of mitochondrial homeostasis by regulating metabolite exchange through the outer membrane. ${ }^{33,34}$ If IGF-1 exerted its protective role solely on the mitochondria and not only on cytosolic constituents, then, in our in vitro system we would expect no difference in the cytochrome $c$ releasing activity of extracts from cells grown in the presence of 4-OHT with or without serum in the medium. In contrast, we observe an almost total absence of cytochrome $c$ releasing activity when serum was added to the medium, suggesting a more complex action of serum and survival factors in general. It is interesting to speculate that survival factors might act by influencing the pattern of gene expression induced by c-Myc. In line with this hypothesis is the observation that IGF-1 was found to suppress phosphorylation of threonine 58 in the c-Myc transactivation domain. Interestingly, a T58A mutant showed a drastically reduced proapoptotic activity and an increased transforming activity. ${ }^{35}$

We found that the proapoptotic member of the Bcl-2 family, Bid, coeluted, at least in two chromatographic steps, with the c-Myc-induced cytochrome $c$ releasing activity. In contrast, 
Bax was present in the flow through of the $Q$ Sepharose column and it was almost undetectable in the active fractions (Figure 4). We also found that Rat1/MycER ${ }^{\mathrm{TM}}$ cells grown in the presence of 4-OHT showed increased immunoreactivity to an antibody that detects a Bax change in conformation. Bax conformational change has been related to its translocation to the mitochondria and induction of cytochrome $c$ release. Therefore, although Bax is dispensable for cytochrome c release in vitro, we find that it participates in the destabilisation of mitochondria in the intact cells. This apparently contradictory result may be explained by the redundancy in function of the 'multidomain' proapoptotic members of the Bcl-2 family, Bak and Bax. Although these proteins show different subcellular localisation in healthy cells, they multimerise and insert into the OMM following a ' $\mathrm{BH} 3$ only' protein-induced conformational change. ${ }^{36-38}$ It is therefore possible that Bak, which is constitutively present in the purified mouse mitochondria as an integral membrane protein, may replace the Bax protein present in the rat fibroblast extracts in our in vitro assay.

The fact that Bid coeluted with the c-Myc-induced cytochrome $c$ releasing activity initially appeared to tie in with data showing that Fas receptor ligation was essential for c-Mycinduced death. ${ }^{39}$ This work implicated receptor-mediated activation of caspase-8, cleavage of Bid and induction of cytochrome $c$ release with consequent apoptosome formation and caspase- 9 activation in c-Myc-induced apoptosis. In the present study, however, two main observations support a role in apoptosis for full-length Bid in Rat1 fibroblasts: (a) we were unable to detect any truncated Bid after c-Myc activation following 4-OHT treatment and (b) using LacZ cotransfection experiments, we observed synergy in the induction of apoptosis between a cleavage-resistant Bid mutant and cMyc activation (Figure 7b). Rat1 fibroblasts are, in general, refractory to Bid cleavage in response to apoptotic treatments, although Bid from these cells could be cleaved in vitro using purified caspase-8 (Figure $6 \mathrm{~b}$ and data not shown). The lack of Bid cleavage in cells following c-Myc activation, nevertheless, fits with the observation that cytochrome $c$ release induced by $\mathrm{c}-\mathrm{Myc}$ is caspase independent ${ }^{16}$ supporting a model in which Fas ligation cooperates with c-Myc on a parallel pathway. ${ }^{16,29}$ The activity of full-length Bid in this system can therefore only be explained either by invoking a second, as yet unknown, way for Bid to be activated, or by the presence of a coactivator in extracts of cells in which c-Myc has been activated.

It has been shown that caspase-8-induced cleavage products of Bid remain bound in a noncovalent complex. The $\mathrm{NH}_{2}$-terminal glycine generated by the cleavage becomes a substrate for myristoylation, which in turn targets the protein to mitochondria. ${ }^{24}$ Although no major change in Bid conformation has been observed in vitro after caspase-8 cleavage,${ }^{40}$ we are not able to exclude the possibility that an increased flexibility of Bid structure, induced by the cleavage, could help the $\mathrm{BH} 3$ domain to become a better ligand for the multidomain Bcl-2 family members, Bax and Bak. In this scenario, one could imagine the existence of a small ligand that would produce a similar change in Bid conformation without affecting its cleavage status. It would be interesting to investigate whether small lipids such as cardiolipin or phosphatidylglycerol, both of which have been shown to bind Bid, ${ }^{41,42}$ could induce such a conformational change. Alternatively, the binding of such lipids could increase the ability of full-length Bid to target mitochondrial membranes. In line with this notion we have observed, by immunofluorescence, an apparent increase in mitochondrial localisation of endogenous Bid following c-Myc activation (data not shown). Noncovalent interactions of Bid with small molecules of this type may not result in altered migration on sizing columns or $2 \mathrm{D}$ gels.

We considered a further model to explain c-Myc modulation of Bid activity. In this model, c-Myc would modulate the expression or activity of another factor essential for Bid to induce cytochrome $c$ release. In support of this possibility, we show that extracts in which c-Myc has been switched on are capable of 'activating' recombinant Bid added to the reaction. This apparent activation may also depend on the presence in the extracts of molecules responsible for a possible completion of cytochrome $c$ release triggered by Bid. In support of this hypothesis, Ott et al. ${ }^{43}$ have recently shown that cytochrome $c$ release from mitochondria proceeds by a two-step process. Alternatively, c-Myc may regulate a soluble regulator of the putative cytochrome $c$ permeability channel. Cyclophilin D, a component of the permeability transition pore (PTP), implicated in many forms of cell death, ${ }^{44}$ has been shown to be upregulated by c-Myc in microarray studies. ${ }^{45}$ Using a similar approach, our own studies show upregulation of cyclophilin D in human cells in which c-Myc has been activated. We also found that VDAC and the benzodiazapine receptor, two other components of the PTP, are upregulated by c-Myc (II and JD, unpublished observations). The possibility that c-Myc regulates a component of the cytochrome $c$ releasing channel could significantly change our model of c-Myc-induced cytochrome $c$ release, implying direct c-Myc effects on the mitochondria as well as cytosolic constituents.

In a linear model in which c-Myc activates Bid, which in turn induces mitochondrial destabilization, Bid could be indispensable for c-Myc-induced apoptosis. Although we were not able to address this issue directly in Rat1 fibroblasts, it is possible that in intact cells or whole animals, other $\mathrm{BH}$-only proteins could contribute significantly to this process, even though Bid is clearly the most important one in our in vitro system. Bid may not, therefore, be universally required for c-Myc-induced cell death, but may contribute to differing extents in different cell types. c-Myc could modulate the activity of factors essential for the functioning of a subset of $\mathrm{BH} 3$ proteins, or the whole BH3-only family in general.

\section{Materials and Methods}

\section{Cell culture}

Rat1 fibroblasts expressing the 4-OHT conditional allele of c-myc (Rat1/ $\mathrm{MycER}^{\mathrm{TM}}$ ) have been described previously. ${ }^{17}$. Cells were grown in Durbecco's modified Eagle medium (DMEM) supplemented with $10 \%$ FCS. Following serum deprivation for $24 \mathrm{~h}$, c-Myc was activated by addition of $100 \mathrm{~nm} 4-\mathrm{OHT}$ (Sigma) in serum-free medium. For protein purification, cells were grown in $30 \times 1800 \mathrm{~cm}^{2}$ roller bottles, containing $200 \mathrm{ml}$ medium. Bottles were previously equilibrated in $5 \% \mathrm{CO}_{2}$. 


\section{Subcellular fractionation}

Cells from roller bottles were washed with phosphate buffer saline (PBS) and trypsinised for $5 \mathrm{~min}$ at $37^{\circ} \mathrm{C}$. Trypsin was neutralised with DMEM supplemented with $30 \%$ FCS. After centrifugation, cells were washed once with cold PBS supplemented with $1 \mathrm{mM}$ Phenyl-methyl sulphonyl fluoride (PMSF) (Sigma), and briefly washed in lysis buffer $(20 \mathrm{mM}$ HEPES/KOH pH 7.4, $100 \mathrm{mM}$ sucrose, $0.1 \mathrm{mM}$ EGTA, $5 \mathrm{mM} \mathrm{MgCl} 2,1 \mathrm{mM}$ DTT, $1 \mathrm{mM}$ PMSF and $1 \times$ Complete $^{\mathrm{TM}}$ [Roche]). Cells were incubated for $30 \mathrm{~min}$ on ice at a concentration of $40 \times 10^{6}$ cells per $\mathrm{ml}$ of lysis buffer, and then Dounce homogenised until $80-90 \%$ of the cells were trypan blue positive. Nuclei and unbroken cells were centrifuged for $10 \mathrm{~min}$ at $1500 \times g$. The supernatant was further centrifuged for $30 \mathrm{~min}$ at $10,000 \times g$ to pellet the heavy membrane fraction. The soluble fraction was passed through a $0.22 \mu \mathrm{m}$ filter and processed for Western blot analysis or protein purification.

\section{Purification of mitochondria from mouse liver}

Mitochondria were purified essentially as described by Hovious et al. ${ }^{18}$. Briefly, two livers were homogenised in $300 \mathrm{mM}$ sucrose, $10 \mathrm{mM}$ HEPES buffer $\mathrm{pH}$ 7.4. Nuclei and debris were spun down at $600 \times g$ for $5 \mathrm{~min}$. Mitochondria and heavy membranes were pelletted by centrifugation at $8700 \times g$ for $10 \mathrm{~min}$. The pellet was washed once in the same buffer supplemented with $1 \mathrm{mM}$ PMSF and resuspended in $2 \mathrm{ml}$ of mannitolMOPS buffer ( $300 \mathrm{mM}$ mannitol, $5 \mathrm{mM}$ MOPS pH 7.2). The suspension was banded in a 70/30/10\% Percoll (Sigma) step gradient in mannitolMOPS buffer by centrifugation for 30 min at $14400 \times g$ (Beckmann SV40 Ti rotor, brake position zero). Preparation purity was verified by electron microscopy.

\section{Cytochrome $c$ release assay}

The ability of cytoplasmic extracts to induce release of cytochrome $c$ from purified mitochondria was assessed by incubating $30 \mu \mathrm{g}$ of mitochondria with $30 \mu \mathrm{g}$ of extracts from cells treated with or without $4-\mathrm{OHT}$ in $30 \mu \mathrm{l}$ final volume. The reaction was carried at $35^{\circ} \mathrm{C}$ for $1 \mathrm{~h}$ in reaction buffer (250 mM mannitol, $100 \mathrm{mM}$ sucrose, $10 \mathrm{mM} \mathrm{KCl}, 1.5 \mathrm{mM} \mathrm{MgCl}_{2}, 1 \mathrm{mM}$ EDTA, $1 \mathrm{mM}$ EGTA, $1 \mathrm{mM}$ DTT, $20 \mathrm{mM} \mathrm{HEPES} / \mathrm{KOH} \mathrm{pH}$ 7.4) and then centrifuged at $9000 \times g$ for $5 \mathrm{~min}$. The mitochondrial pellet was resuspended in $30 \mu \mathrm{l}$ of reaction buffer containing $1 \%$ Triton. For the measurement of the cytochrome $c$ rate of release, 10,30 and $50 \mu \mathrm{g}$ of extract from Rat1/MycER ${ }^{\mathrm{TM}}$ cells treated with or without 4-OHT were incubated for 1,2 and $3 \mathrm{~h}$ with $30 \mu \mathrm{g}$ of pure mitochondria. The amount of cytochrome $c$ released was quantified by densitometry. The initial velocity was calculated graphically and plotted against the amount of extract used.

\section{Western blot analysis}

To analyse the amount of cytochrome $c$ released from purified mouse liver mitochondria, $2 \mu$ l of reaction supernatant or solubilised pellet were loaded on a $15 \%$ SDS-PAGE. Gels were transferred on Immobilon PVDF membranes (Millipore) and stained for cytochrome $c$ using the monoclonal antibody $7 \mathrm{H} 8.2 \mathrm{C} 12$ (Pharmingen). The presence of $\mathrm{Bid}$ in the chromatographic fractions was tested by using a goat polyclonal antiBid antibody (R\&D Systems). Bax antibody (TL41) was produced by immunising rabbits with a KLH-conjugated peptide spanning amino acids 57-72 around Bax BH3 domain.

\section{Protein purification}

Cytoplasmic extracts from $3 \times 10^{9}$ cells were brought to a conductivity corresponding to $150 \mathrm{mM} \mathrm{NaCl}$ in Buffer A (20 mM HEPES/ $\mathrm{NaOH} \mathrm{pH} \mathrm{7.4,.}$ $0.5 \mathrm{mM}$ EDTA, $1 \mathrm{mM}$ DTT, $1 \mathrm{mM}$ PMSF), then $0.22 \mu \mathrm{m}$ filtered and loaded on a $20 \mathrm{ml}$-bed volume $Q$ Sepharose Fast Flow column (Amersham Biosciences) previously equilibrated in Buffer $A / 150 \mathrm{mM} \mathrm{NaCl}$. The chromatography was performed at $4^{\circ} \mathrm{C}$ using an Äkta purifier (Amersham Biosciences). The column was washed with five column volumes (CV) of equilibration buffer and eluted with a $10 \mathrm{CV}$ linear gradient from 150 to $700 \mathrm{mM} \mathrm{NaCl}$ in Buffer A. Fractions of $2 \mathrm{ml}$ were collected. Fractions active for cytochrome $c$ release were pooled and concentrated 2.5 -fold on a PEG bed. After centrifugation, the solution was loaded on a HiLoad 16/ 60 Superdex 200 (Amersham Biosciences), equilibrated in $20 \mathrm{mM}$ HEPES/NaOH pH 7.4, $200 \mathrm{mM} \mathrm{NaCl}, 0.5 \mathrm{mM}$ EDTA, $1 \mathrm{mM}$ DTT, and $1 \mathrm{mM}$ PMSF.

\section{Production and purification of recombinant proteins}

Bid cDNA was amplified using the polymerase chain reaction (PCR) from a HeLa cDNA library and cloned $(\mathrm{Ncol} / \mathrm{BamHI})$ in the pQE60 vector (QIAGEN) in frame with a C-terminal $6 \times$ Histidine Tag. The cDNA encoding for Bcl- $\mathrm{X}_{\mathrm{L}}$ was cloned (Sphl/Sacl) in the pQE30 vector (QIAGEN). Protein expression and purification were carried out according to the manufacturer's instructions. Most of Bid protein eluted at $60 \mathrm{mM}$ imidazole from the Nickel NTA agarose (QIAGEN). Bcl- $X_{L}$ eluted at $300 \mathrm{mM}$ imidazole. Purified proteins were dialysed against $20 \mathrm{mM} \mathrm{HEPES/}$ $\mathrm{KOH}$ pH 7.4, 10\% sucrose, $50 \mathrm{mM} \mathrm{KCl,} 1 \mathrm{mM} \mathrm{DTT}, 1 \mathrm{mM} \mathrm{PMSF}$, aliquoted and stored at $-80^{\circ} \mathrm{C}$.

\section{LacZ cotransfections}

Rat1/MycER ${ }^{\mathrm{TM}}$ cells $\left(5 \times 10^{6}\right)$ were electroporated in $10 \% \mathrm{FCS}$ with $10 \mu \mathrm{g}$ of pcDNA3.1/LacZ. plus $30 \mu \mathrm{g}$ of pcDNA3.1 (Vec), $30 \mu \mathrm{g}$ of pcDNA3.1/ Bid-his (Bid) or $30 \mu \mathrm{g}$ of pcDNA3.1/BidD60E-his (BidDE). Cells $\left(2 \times 10^{5}\right)$ from each transfection were seeded in duplicate in six- well plates overnight in $10 \%$ FCS. The day after, cells were serum starved in $1 \%$ FCS for $24 \mathrm{~h}$. The samples were treated with or without $100 \mathrm{nM} 4-\mathrm{OHT}$ for $16 \mathrm{~h}$, washed in PBS and fixed with $0.25 \%$ glutaraldehyde in PBS for $15 \mathrm{~min}$. Cells were stained with filtered X-Gal solution $\left(0.2 \% \mathrm{X}\right.$-Gal, $2 \mathrm{mM} \mathrm{MgCl}_{2}$, $\left.5 \mathrm{mM} \mathrm{K}_{4} \mathrm{Fe}(\mathrm{CN})_{6}, 5 \mathrm{mM} \mathrm{K}_{3} \mathrm{Fe}(\mathrm{CN})_{6}\right)$ for $16 \mathrm{~h}$ at $37^{\circ} \mathrm{C}$. After washing with PBS, the number of blue cells was counted in each sample. The total number of cells was extrapolated by counting the number of cells present in $1 \mathrm{~cm}^{2}$ of plate. The per cent of decrease of blue cells was derived by comparing the percentages of blue cells left in the samples coming from the same transfection, treated or not with 4-OHT. The experiment has been carried in duplicate.

\section{Isoelectrofocusing}

Rat1/MycER ${ }^{\mathrm{TM}}$ cells $\left(2 \times 10^{6}\right)$ were serum starved for $24 \mathrm{~h}$ and then treated with or without $4-\mathrm{OHT}$ for $8 \mathrm{~h}$. Cell pellets were lysed directly in rehydration solution (8 M urea, $0.5 \%$ CHAPS, $0.2 \%$ DTT, $0.5 \%$ IPG buffer, $0.002 \%$ bromophenol blue). Rehydration and first dimension were carried using an Ettan IPGphor apparatus (Amersham Biosciences) according to the manufacturer's instructions. Focused $18-\mathrm{cm}$ strips (3-10 pH interval) were equilibrated in denaturing solution $(2 \% \mathrm{SDS}, 50 \mathrm{mM} \mathrm{Tris} / \mathrm{HCl} \mathrm{pH} 8.8$, $6 \mathrm{M}$ urea, $30 \%$ glycerol, $0.002 \%$ bromophenol blue, $0.2 \%$ DTT). Thiol groups were blocked using $25 \mathrm{mg} / \mathrm{ml}$ of iodoacetamide according to the 
manufacturer's instruction. A $7 \mathrm{~cm}$ of the strip corresponding to the $\mathrm{pH}$ interval 5-6 was cut out and loaded on a 15\% SDS-PAGE.

\section{Analysis of Bax conformational change}

Cells were seeded onto glass coverslips in six-well plates and allowed to attach and grow for $24 \mathrm{~h}$ in DMEM/10\% FCS. The medium was then replaced by DMEM/0.2\% FCS for a further $24 \mathrm{~h}$. c-MycER was activated by the addition of $4-\mathrm{OHT}$ for 4 or $6 \mathrm{~h}$. Control wells were treated with an equal volume of $\mathrm{EtOH}$ vehicle. After rinsing twice with cold PBS, cell monolayers were fixed by addition of $1 \%$ paraformaldehyde in PBS for $5 \mathrm{~min}$ at room temperature. Coverslips were washed three times in PBS and incubated with $6 \mathrm{~A} 7$ anti-Bax monoclonal antibody (Trevigen) diluted 1/ 200 in PBS containing $500 \mu \mathrm{g} / \mathrm{ml}$ digitonin at $4^{\circ} \mathrm{C}$ overnight. After washing three times in PBS, bound antibody was detected by incubation with cy3conjugated anti-mouse IgG (Amersham Biosciences) diluted 1/200 in 1\% BSA/PBS. Coverslips were then washed three times in PBS, mounted with ProLong Antifade (Molecular Probes) and analysed by fluorescence microscopy (Zeiss, UK). The percentage of Bax-positive cells was quantified by counting a minimum of 500 cells in five randomly chosen fields for each treatment/time point. Positive cells showing a strong, punctate staining pattern are expressed as a percentage of the total number of cells analysed. Values represent the mean and variation of a typical experiment performed in duplicate.

\section{Acknowledgements}

We thank Patricia Warne for antibody purification, the Electron Microscopy unit of Cancer Research UK for assessing the purity of mitochondrial preparations, Victoria Cowling and Patrizia Stoppelli for their critical review of the manuscript, Philippe Juin for the stimulating critical support of this work, and all the members of the Signal Transduction Laboratory for helpful discussions. II was recipient of an EMBO fellowship.

\section{References}

1. Grandori C, Cowley SM, James LP and Eisenman RN (2000) The Myc/Max Mad network and the transcriptional control of cell behavior. Annu. Rev. Cell. Dev. Biol. 16: 653-699

2. Evan GI, Wyllie AH, Gilbert CS, Littlewood TD, Land H, Brooks M, Waters CM, Penn LZ and Hancock DC (1992) Induction of apoptosis in fibroblasts by c-myc protein. Cell. 69: 119-128

3. Harrington EA, Bennett MR, Fanidi A and Evan GI (1994) c-Myc-induced apoptosis in fibroblasts is inhibited by specific cytokines. EMBO J 13: 32863295

4. Hueber AO and Evan Gl (1998) Traps to catch unwary oncogenes. Trends Genet. 14: 364-367

5. Fanidi A, Harrington EA and Evan Gl (1992) Cooperative interaction between c-myc and bcl-2 proto-oncogenes. Nature 359: 554-556

6. Strasser A, Harris AW, Bath ML and Cory S (1990) Novel primitive lymphoid tumours induced in transgenic mice by cooperation between myc and bcl-2. Nature 348: 331-333

7. Gross A, McDonnell JM and Korsmeyer SJ (1999) BCL-2 family members and the mitochondria in apoptosis. Genes Dev 13: 1899-1911

8. Chen-Levy Z, Nourse J and Cleary ML (1989) The bcl-2 candidate protooncogene product is a 24-kilodalton integral-membrane protein highly expressed in lymphoid cell lines and lymphomas carrying the $t(14 ; 18)$ translocation. Mol. Cell. Biol. 9: 701-710

9. Hockenbery D, Nunez G, Milliman C, Schreiber RD and Korsmeyer SJ (1990) $\mathrm{Bcl}-2$ is an inner mitochondrial membrane protein that blocks programmed cell death. Nature 348: 334-336
10. Vander Heiden MG, Chandel NS, Li XX, Schumacker PT, Colombini M and Thompson CB (2000) Outer mitochondrial membrane permeability can regulate coupled respiration and cell survival. Proc. Natl. Acad. Sci. USA 97: 4666-4671

11. Vander Heiden MG, Li XX, Gottleib E, Hill RB, Thompson CB and Colombini M (2001) Bcl-XL promotes the open configuration of the voltage-dependent anion channel and metabolite passage through the outer mitochondrial membrane. J. Biol. Chem. 276: 19414-19419

12. Minn AJ, Kettlun CS, Liang H, Kelekar A, Vander Heiden MG, Chang BS, Fesik SW, Fill M and Thompson CB (1999) BCl-xL regulates apoptosis by heterodimerization-dependent and -independent mechanisms. EMBO J. 18: $632-643$

13. Datta SR, Dudek H, Tao X, Masters S, Fu H, Gotoh Y and Greenberg ME (1997) Akt phosphorylation of BAD couples survival signals to the cell- intrinsic death machinery. Cell 91: 231-241

14. Puthalakath H, Huang DC, O'Reilly LA, King SM and Strasser A (1999) The proapoptotic activity of the Bcl-2 family member Bim is regulated by interaction with the dynein motor complex. Mol. Cell 3: 287-296

15. Desagher S, Osen-Sand A, Nichols A, Eskes R, Montessuit S, Lauper S, Maundrell K, Antonsson B and Martinou JC (1999) Bid-induced conformational change of Bax is responsible for mitochondrial cytochrome $c$ release during apoptosis. J. Cell Biol. 144: 891-901

16. Juin P, Hueber AO, Littlewood T and Evan G (1999) c-Myc-induced sensitization to apoptosis is mediated through cytochrome $c$ release. Genes Dev. 13: 1367-1381

17. Littlewood TD, Hancock DC, Danielian PS, Parker MG and Evan Gl (1995) A modified oestrogen receptor ligand-binding domain as an improved switch for the regulation of heterologous proteins. Nucleic Acids Res. 23: 1686-1690

18. Hovius R, Lambrechts H, Nicolay K and de Kruijff B (1990) Improved methods to isolate and subfractionate rat liver mitochondria. Lipid composition of the inner and outer membrane. Biochim. Biophys. Acta 1021: $217-726$

19. Luo X, Budihardjo I, Zou H, Slaughter C and Wang X (1998) Bid, a $\mathrm{Bc} 2$ interacting protein, mediates cytochrome $c$ release from mitochondria in response to activation of cell surface death receptors. Cell 94: 481-490

20. Jurgensmeier JM, Xie Z, Deveraux Q, Ellerby L, Bredesen D and Reed JC (1998) Bax directly induces release of cytochrome $C$ from isolated mitochondria. Proc Natl Acad Sci USA. 95: 4997-5002

21. Narita M, Shimizu S, Ito T, Chittenden T, Lutz RJ, Matsuda $H$ and Tsujimoto $Y$ (1998) Bax interacts with the permeability transition pore to induce permeability transition and cytochrome $c$ release in isolated mitochondria. Proc Natl Acad Sci USA. 95: 14681-14686

22. Yin XM, Wang K, Gross A, Zhao Y, Zinkel S, Klocke B, Roth KA and Korsmeyer SJ (1999) Bid-deficient mice are resistant to Fas-induced hepatocellular apoptosis. Nature 400: 886-891

23. Downward J (1999) How BAD phosphorylation is good for survival. Nat Cell Biol. 1: E33-E35

24. Zha J, Weiler S, Oh KJ, Wei MC and Korsmeyer SJ (2000) Posttranslational Nmyristoylation of BID as a molecular switch for targeting mitochondria and apoptosis. Science. 290: 1761-1765

25. Desagher S, Osen-Sand A, Montessuit S, Magnenat E, Vilbois F, Hochmann A, Journot L, Antonsson B and Martinou JC (2001) Phosphorylation of bid by casein kinases I and II regulates its cleavage by caspase 8. Mol. Cell 8: 601611

26. Eskes R, Desagher S, Antonsson B and Martinou JC (2000) Bid induces the oligomerization and insertion of Bax into the outer mitochondrial membrane. Mol Cell Biol. 20: 929-935

27. Hsu YT and Youle RJ (1998) Bax in murine thymus is a soluble monomeric protein that displays differential detergent-induced conformations. J. Biol. Chem. 273: 10777-10783

28. Makin GW, Corfe BM, Griffiths GJ, Thistlethwaite A, Hickman JA and Dive C (2001) Damage-induced Bax N-terminal change, translocation to mitochondria and formation of Bax dimers/complexes occur regardless of cell fate. EMBO J. 20: $6306-6315$

29. Evan $G$ and Littlewood T (1998) A matter of life and cell death. Science 281: $1317-1322$

30. Downward J (1998) Ras signalling and apoptosis. Curr. Opin. Genet. Dev. 8: 49-54. 
Proapoptotic BAX and BAK: a requisite gateway to mitochondrial dysfunction and death. Science 292: 727-730

38. Zong WX, Lindsten T, Ross AJ, MacGregor GR and Thompson CB (2001) $\mathrm{BH} 3$-only proteins that bind pro-survival Bcl-2 family members fail to induce apoptosis in the absence of Bax and Bak. Genes Dev. 15: 1481-1486

39. Hueber AO, Zornig M, Lyon D, Suda T, Nagata S and Evan GI (1997) Requirement for the CD95 receptor-ligand pathway in c-Myc-induced apoptosis. Science 278: 1305-1309

40. Chou JJ, Li H, Salvesen GS, Yuan J and Wagner G (1999) Solution structure of $\mathrm{BID}$, an intracellular amplifier of apoptotic signaling. Cell 96: 615-624

41. Esposti MD, Erler JT, Hickman JA and Dive C (2001) Bid, a widely expressed proapoptotic protein of the $\mathrm{Bcl}-2$ family, displays lipid transfer activity. Mol. Cell. Biol. 21: 7268-7276

42. Lutter M, Fang M, Luo X, Nishijima M, Xie X and Wang X (2000) Cardiolipin provides specificity for targeting of tBid to mitochondria. Nat. Cell. Biol. 2: 754 761

43. Ott M, Robertson JD, Gogvadze V, Zhivotovsky B and Orrenius S (2002) Cytochrome $c$ release from mitochondria proceeds by a two-step process. Proc. Natl. Acad. Sci. USA. 99: 1259-1263

44. Zamzami N and Kroemer G (2001) The mitochondrion in apoptosis: how Pandora's box opens. Nat. Rev. Mol. Cell. Biol. 2: 67-71

45. Guo QM, Malek RL, Kim S, Chiao C, He M, Ruffy M, Sanka K, Lee NH, Dang $\mathrm{CV}$ and Liu ET (2000) Identification of c-myc responsive genes using rat CDNA microarray. Cancer Res. 60: 5922-5928 